ÉGYPTE monde arabe

\section{Égypte/Monde arabe}

$12-13 \mid 1993$

Une économie en transition

\title{
Conflits communautaires : interprétations et solutions
}

Al-Ahrâm, 26 mai 1992

\section{Galal Amin}

Traducteur : Delila Dizdarevic

\section{(2) OpenEdition \\ Journals}

Édition électronique

URL : https://journals.openedition.org/ema/1276

DOI : 10.4000/ema.1276

ISSN : 2090-7273

Éditeur

CEDEJ - Centre d'études et de documentation économiques juridiques et sociales

Édition imprimée

Date de publication : 31 mars 1993

Pagination : 251-253

ISSN : 1110-5097

\section{Référence électronique}

Galal Amin, «Conflits communautaires : interprétations et solutions », Égypte/Monde arabe [En ligne], 12-13 | 1993, mis en ligne le 08 juillet 2008, consulté le 07 juillet 2022. URL : http:// journals.openedition.org/ema/1276 ; DOI : https://doi.org/10.4000/ema.1276

Ce document a été généré automatiquement le 7 juillet 2022.

Tous droits réservés 


\section{Conflits communautaires : interprétations et solutions}

Al-Ahrâm, 26 mai 1992

\section{Galal Amin}

Traduction : Delila Dizdarevic

1 J'ai le sentiment - je ne le dissimule pas - que bon nombre des commentaires suscités par les affrontements survenus récemment à Sanbou, Dayrout et Assiout sont davantage un moyen de soulager sa conscience qu'une réaction sincère à des événements qui meurtrissent au premier chef les musulmans, ensuite les coptes. La plupart de ces commentaires reste en deçà du niveau de responsabilité qu'implique ce genre d'événements...

2 Par exemple, je ne pense pas qu'il soit opportun, dans le cas qui nous occupe, de souligner le rôle d'éléments $^{\circ}$ suspects ${ }^{\circ}$ » venant de l'étranger. La théorie de la conspiration ne mène pas à grand-chose. La monstruosité de l'acte ne repose pas tant sur sa préméditation et sur ses objectifs que sur les sentiments qui ont poussé les criminels à l'accomplir. En outre, il n'y a pas de preuves décisives en faveur d'une intervention de l'extérieur.

3 De même, insister sur le fait que l'islam a, tout au long de l'histoire, respecté les coptes (et les minorités en général) est en la circonstance inutile. Personne - ni en Orient ni en Occident - ne nie la tolérance religieuse dont ont fait preuve les musulmans au fil des siècles. Le problème, ici, ne concerne pas la position de l'islam envers les minorités, mais l'attitude concrète de certains musulmans envers certains coptes, dans tel village, à telle occasion. Impossible, ici, de recourir au discours sur l'attitude des musulmans en général, ni de débattre de ce qui a été par rapport à ce qui devrait être. À moins que les mérites des Égyptiens en général puissent atténuer le crime de l'un d'entre eux, ou que la seule mention de ${ }^{\circ}$ musulman ${ }^{\circ} »$ sur un certificat de naissance justifie toute déviation.

4 On ne peut pas davantage, à mon avis, invoquer par trop la vengeance comme mobile essentiel. Sans doute a-t-elle joué un certain rôle ${ }^{\circ}$; mais cela, en soi, n'explique rien. Même en ayant présentes à l'esprit toutes les circonstances, le désir de se venger ne justifie en aucun cas l'ampleur du crime, son caractère monstrueux ni l'identité des 
victimes. Car au meurtre lui-même s'ajoutent l'audace des meurtriers, leur stupéfiante indifférence envers l'ordre public, le pouvoir, les sentiments du peuple, avant et après le crime. Il est inadmissible d'essayer de prétendre que ${ }^{\circ}$ tout va pour le mieux $^{\circ} »$ alors que nous en sommes fort loin, cela dans le but de rassurer l'opinion. Que chacun exprime donc son point de vue, et peut-être trouverons-nous une solution.

Passons aux "remèdes proposés ». Il s'agit là aussi d'un moyen de soulager sa conscience. Les remèdes en question laissent perplexes. La " ${ }^{\circ}$ démocratie ${ }^{\circ}$ » - malgré tous les beaux discours que l'on tient à son propos - ne saurait être une " ${ }^{\circ}$ solution ${ }^{\circ}$ » à court terme $e^{\circ}$ combien d'années faudra-t-il attendre pour parvenir à un niveau satisfaisant de démocratie ${ }^{\circ}$ ? Combien d'affrontements peuvent avoir lieu d'ici là?? Davantage de démocratie ${ }^{\circ}$ ? Certainement, et quelles que soient les circonstances ${ }^{\circ}$; est-il vraiment indispensable de le répéter dans le cas qui nous occupe ${ }^{\circ}$ ?

Il en est de même pour le " $^{\circ}$ projet national ${ }^{\circ}$ » qui rassemblerait tous les citoyens musulmans et coptes. Ce sont là encore de belles paroles qui ne nous avancent en rien. La bonne volonté ne suffit pas à édifier un " $^{\circ}$ projet national ${ }^{\circ} »^{\circ}$; il ne s'agit pas d'un plan économique ou architectural qu'on trace sur le papier avant de procéder à sa réalisation ${ }^{\circ}$; c'est le produit du temps et des circonstances. Ce n'est pas un produit fabriqué, on ne peut forcer personne à l'accepter et chacun ne peut y adhérer que de façon spontanée. On ne peut différer constamment la résolution des conflits intercommunautaires sous prétexte d'attendre la réalisation de ce projet national fantôme.

Déclarer qu'il est nécessaire de faire face aux problèmes d'ordre économique et social au chômage en particulier - est fort raisonnable, mais cela ne nous satisfait pas pour autant $^{\circ}$ : conflits inter-communautaires ou pas, résoudre les problèmes économiques et mettre fin au chômage est, de toute façon, indispensable. Il est plus facile de soulever ces difficultés que de les affronter. Bien des conditions ne sont pas remplies pour cela. En outre, plusieurs des projets proposés par les institutions internationales sont en contradiction profonde avec la lutte contre le chômage ${ }^{\circ}$ : il est même probable qu'ils l'accentueraient. Faut-il avoir recours au Fonds social quand il est question de conflits intercommunautaires ${ }^{\circ}$ ? Je ne le crois pas.

8 Il faut porter notre attention - et cela sans attendre - sur les programmes scolaires de manière à adapter l'enseignement aux valeurs de tolérance religieuse, de fraternité et d'amour prônées par les slogans. Bien que la nécessité en ait été proclamée plus d'une fois, la réalisation en a été, de façon injustifiable, différée. Mais ce n'est pas uniquement à cause des conflits intercommunautaires que l'on devrait réformer les programmes scolaires $^{\circ}$; il y a bien d'autres raisons de le faire, raisons d'ordre éducatif, psychologique... Et les effets de cette réforme n'apparaîtront qu'à long terme. Je voudrais souligner l'importance des médias, et tout spécialement de la télévision ${ }^{\circ}$ : son rôle dans la formation de l'opinion ne peut être comparé avec celui d'autres institutions.

9 L'utilisons-nous de notre mieux, eu égard au problème qui nous occupe ${ }^{\circ}$ ? A la télévision, on proclame l'état d'urgence dès qu'un incident menace de retarder le tournage des « ${ }^{\circ}$ Devinettes du Ramadan ${ }^{\circ} » . .$. Qu'en est-il quand il faut affronter des événements comme ceux d'Assiout et de Dayroutº Je ne crois pas que l'Égypte soit dépourvue de talents artistiques capables de produire rapidement des films de bonne qualité. La beauté, l'art dépouillé de clichés et de slogans rapprocherait les communautés. Est-il vraiment impossible de développer chez les enfants l'amour de camarades d'autres confessions ${ }^{\circ}$ ? Est-il vraiment impossible qu'un jeune homme 
impulsif y réfléchisse à deux fois avant d'attaquer les édifices religieux d'une autre communauté que la sienne ${ }^{\circ}$ ?

Toute personne chargée d'une mission éducative - et, en général, toute personne douée de bon sens - est consciente que parler de tolérance, d'amour et de fraternité est une chose, et que faire agir ses semblables dans ce sens en est une autre ${ }^{\circ}$ que les slogans n'ont aucun effet sur quiconque ${ }^{\circ}$; que bourrer de grands mots le crâne d'un écolier ne l'empêchera pas de se comporter d'une façon qui les contredit.

11 Les quelques programmes télévisés et radiophoniques consacrés à notre problème, ainsi que ce qu'en disent les livres scolaires et certains articles de journaux, sont dérisoires. Rien de tout cela ne nous fait avancer d'un pouce. Nous avons besoin de véritables oeuvres d'art, réalisées par des artistes dignes de ce nom qui croient de tout coeur en notre cause (et Dieu merci, il y en a beaucoup en Égypte), prêts à travailler sans relâche pour créer des émissions, drames, feuilletons de qualité. L'effet pourrait en être immédiat. On ne pourrait plus, sans honte, commettre des actes de violence envers des personnes appartenant à une autre religion que la sienne.

12 Enfin, que disent les imams dans les mosquées chaque semaine ${ }^{\circ}$ ? Est-il si difficile d'exercer un contrôle sur leurs discours ${ }^{\circ}$ ? Nous accusons ceux qui empêchent certains livres d'être publiés, puis des arguments s'élèvent en faveur de la censure. Savons-nous que certains ouvrages non censurés, vendus sur les trottoirs, encouragent l'intolérance religieuse ${ }^{\circ}$ ? Personne n'en réclame la saisie, quoiqu'ils menacent l'ordre public et la sécurité bien plus que la saisie elle-même.

13 Ceci est une petite partie de ce qui devrait être fait sans délai. [...]

\section{INDEX}

Mots-clés : conflits communautaires, Coptes, violence 